\title{
Intake of carbohydrates and SFA and risk of CHD in middle-age adults: the Hordaland Health Study (HUSK)
}

\author{
Teresa R Haugsgjerd 1,*, Grace M Egeland ${ }^{1,2}$, Ottar K Nygård ${ }^{3,4}$, Jannicke Igland ${ }^{1}$, \\ Gerhard Sulo5,6, Vegard Lysne ${ }^{4}$, Kathrine J Vinknes ${ }^{7}$, Kjetil Bjornevik ${ }^{1,8}$ and \\ Grethe S Tell ${ }^{1,9}$ \\ 'Department of Global Public Health and Primary Care, University of Bergen, Årstadveien 17, 5009 Bergen, Norway: \\ ${ }^{2}$ Health Registries, Research and Development, The Norwegian Institute of Public Health, Bergen, Norway: \\ ${ }^{3}$ Department of Heart Disease, Haukeland University Hospital, Bergen, Norway: ${ }^{4}$ Department of Clinical Science, \\ Centre for Nutrition, University of Bergen, Bergen, Norway: ${ }^{5}$ Centre for Disease Burden, Norwegian Institute of Public \\ Health, Bergen, Norway: ${ }^{6}$ Oral Health Centre of Expertise in Western Norway, Bergen, Norway: ${ }^{7}$ Faculty of \\ Medicine, Institute of Basic Medical Sciences, University of Oslo, Oslo, Norway: ${ }^{8}$ Department of Nutrition, Harvard \\ T.H. Chan School of Public Health, Boston, MA, USA: ${ }^{9}$ Division of Mental and Physical Health, Norwegian Institute of \\ Public Health, Bergen, Norway
}

Submitted 11 October 2019: Final revision received 21 July 2020: Accepted 29 July 2020: First published online 10 September 2020

\begin{abstract}
Objective: Limiting SFA intake may minimise the risk of CHD. However, such reduction often leads to increased intake of carbohydrates. We aimed to evaluate associations and the interplay of carbohydrate and SFA intake on CHD risk.

Design: Prospective cohort study.

Setting: We followed participants in the Hordaland Health Study, Norway from 1997-1999 through 2009. Information on carbohydrate and SFA intake was obtained from a FFQ and analysed as continuous and categorical (quartiles) variables. Multivariable Cox regression estimated hazard ratios (HR) and $95 \%$ CI. Theoretical substitution analyses modelled the substitution of carbohydrates with other nutrients. CHD was defined as fatal or non-fatal CHD (ICD9 codes 410-414 and ICD10 codes I20-I25).

Participants: 2995 men and women, aged 46-49 years.

Results: Adjusting for age, sex, energy intake, physical activity and smoking, SFA was associated with lower risk $\left(\mathrm{HR}_{\mathrm{Q} 4} v\right.$. Q1 $\left.0 \cdot 44,95 \% \mathrm{CI} 0 \cdot 26,0 \cdot 76, P_{\text {trend }}=0 \cdot 002\right)$. For carbohydrates, the opposite pattern was observed $\left(\mathrm{HR}_{\mathrm{Q} 4} v\right.$. Q1 $2 \cdot 10,95 \%$ CI $\left.1.22,3.63, P_{\text {trend }}=0.003\right)$. SFA from cheese was associated with lower CHD risk $\left(\mathrm{HR}_{\mathrm{Q} 4} v \cdot \mathrm{Q} 10.44,95 \% \mathrm{CI} 0 \cdot 24,0.83, P_{\text {trend }}=0.006\right)$, while there were no associations between SFA from other food items and CHD. A 5 E\% substitution of carbohydrates with total fat, but not SFA, was associated with lower CHD risk (HR 0.75, $95 \%$ CI 0.62, 0.90).

Conclusions: Higher intake of predominantly high glycaemic carbohydrates and lower intake of SFA, specifically lower intake from cheese, were associated with higher CHD risk. Substituting carbohydrates with total fat, but not SFA, was associated with significantly lower risk of CHD.
\end{abstract}

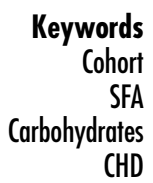

According to Ancel Keys 'diet-heart' hypothesis, a habitually high intake of SFA may increase the risk of CHD due to increases in serum total cholesterol $(\mathrm{TC})^{(1,2)}$. Mensink \& $\operatorname{Katan}^{(3)}$ published a meta-analysis in 1992, including twenty-seven controlled trials, concluding that the most favourable lipoprotein profile for CHD was achieved if SFA were replaced by unsaturated fatty acids, keeping the intake of total fat unchanged.
The discovery of the additional pathways leading from diet to CHD has made the 'diet-heart' hypothesis more complex $^{(4)}$. Advice to reduce SFA as a means to prevent CHD may have, indirectly, increased the intake of carbohydrates ${ }^{(5,6)}$. While carbohydrates have been considered a basis of a healthy diet, with grain products at the base of the Food Guide Pyramid ${ }^{(7)}$, a diet rich in added sugars and refined grains promotes visceral adiposity and reduces 
energy expenditure ${ }^{(8-10)}$, raising concerns of the potential for increased CHD risk. On the other hand, if dietary carbohydrates are replaced by fat, the postprandial rise in blood glucose and insulin decreases while glucagon secretion increases, resulting in lower CHD risk $^{(11-14)}$. However, among adults with obesity, Hall et al. ${ }^{(15)}$ found that restriction of dietary fat was associated with a slightly larger body fat loss than restriction of dietary carbohydrates. Also of twenty-nine diets with different macronutrient compositions tested in mice, only high-fat diets led to overconsumption and weight gain $^{(16)}$. A review indicated that greater high glycaemic index carbohydrate intake was associated with a higher risk of CVD compared with SFA intake ${ }^{(17)}$. Further, recent prospective studies and reviews as well as meta-analyses have shown inconclusive associations between self-reported intakes of either SFA or carbohydrates and fatal and non-fatal $\mathrm{CHD}^{(18-23)}$.

Given the inconsistencies in the literature, the objective of the current study was to evaluate the associations of carbohydrate and SFA intakes with incident CHD in a sample of middle-age community-dwelling Norwegian adults, where the intake of carbohydrates varied from 21 to 74 energy percentage (E\%) with a median intake of $49 \mathrm{E} \%$, and where the intake of SFA varied from 4 to $25 \mathrm{E} \%$ with a median intake of $13 \mathrm{E} \%$.

\section{Participants and methods}

\section{Study population}

The current study is a prospective cohort study of participants in the community-based Hordaland Health Study (HUSK) (https://husk-en.w.uib.no/). The recruitment was based on a cohort from 1992 to 1993 (The Hordaland Homocysteine Study). In 1997-1999, all living cohort members born 1950-1951 and residing in the city of Bergen or the neighbouring suburban municipalities were invited to participate in HUSK. The baseline examinations for the current study were conducted during 1997-1999 as a collaboration between the National Health Screening Service (now The Norwegian Institute of Public Health), The University of Bergen and local health services. The participation rate was $77 \%$. Participants underwent a brief health examination and provided a non-fasting blood sample. Information on lifestyle was collected via self-administered questionnaires. A semi-quantitative FFQ was completed by $87 \%$ of the participants. A total of 3107 participants aged 46-49 years who answered the FFQ were eligible to be included in the current study.

We excluded twenty-two men and five women who reported prior $\mathrm{CHD}$, and four men and nineteen women due to missing information. Further, we excluded twentyseven men and thirty-five women who reported extreme energy intakes (below the 1st percentile: $<4707.8 \mathrm{~kJ}$ for men and $2951.8 \mathrm{~kJ}$ for women; or above the 99th percentile: $>18907.9 \mathrm{~kJ}$ for men and $>14944.0 \mathrm{~kJ}$ for women). The final study population thus included 2995 participants.

\section{Dietary assessment}

Information on food intake was obtained at baseline (1997-1999) using a 169-item past-year semi-quantitative FFQ, a slightly modified version of a previously described $\mathrm{FFQ}^{(24)}$. The validity study of the previous version of the FFQ in a younger population found that the Spearman correlation coefficients between intake of SFA and carbohydrates estimated by the FFQ $v$. weighed food records were 0.44 and 0.57 , respectively ${ }^{(24)}$. The FFQ was handed out on the day of the health examination, filled out at home and returned by mail to the HUSK project centre. It includes frequency alternatives (from once a month to several times/ d), the number of units eaten and portion sizes (e.g., slices, glasses and spoons) to capture the habitual diet during the past year. The information is presented as individual food or beverage items, food groups and nutrients. Daily nutrient intakes were computed from a database and software system developed at the Department of Nutrition, University of Oslo (KBS, version 3.2). The nutrient database is primarily based on the official Norwegian food composition table ${ }^{(25)}$. During dietary data collection in 1997-1999, margarine was undergoing rapid compositional changes where large amounts of trans-fatty acids, an important contributor to unsaturated fat ${ }^{(5,26)}$, were being reduced due to legislation in Norway ${ }^{(26)}$. Further, prospectively, there were other changes to unsaturated fat sources ${ }^{(5)}$; thus, unsaturated fat was not evaluated as a primary dietary exposure in the current study.

Measurements used as independent variables in the current study are the total dietary amount of SFA and carbohydrates, as well as intake of SFA and carbohydrates from different food items. All are expressed as $\mathrm{E} \%$.

\section{Health examination and bealth habits}

Baseline examinations included measurements of height, weight, waist circumference, blood pressure and nonfasting blood samples. After at least 2 min seated rest, systolic blood pressure and diastolic blood pressure were measured three times (Dinamap 845 XT equipment (Criticon)). Serum samples of TC, HDL-cholesterol, TAG and glucose were analysed within $7 \mathrm{~d}$ at the Department of Clinical Chemistry, Ullevål University Hospital, Oslo, using enzymatic methods with reagents from Boehringer Mannheim (Roche). The Friedewald equation was used for the calculation of LDL-cholesterol. Information on educational level and medication use was self-reported.

Hypertension was considered present if the mean of at least two consecutive measurements of systolic blood pressure was $\geq 140 \mathrm{mmHg}$ or diastolic blood pressure $\geq 90 \mathrm{mmHg}$ or if the use of medication for hypertension was self-reported. 
Participants taking diabetes medications or reported having been diagnosed with diabetes were defined as having diabetes. Also, participants with a serum glucose level $>7 \mathrm{mmol} / \mathrm{l}$ who had not eaten a meal during the last $8 \mathrm{~h}$, or with a glucose level $>11.1 \mathrm{mmol} / \mathrm{l}$ and $<8 \mathrm{~h}$ since their last meal, were defined as having diabetes. Pre-diabetes was defined as having glucose levels between 5.6 and $7 \mathrm{mmol} / \mathrm{l}$ at least $8 \mathrm{~h}$ after their last meal or between 7.8 and $11 \mathrm{mmol} / 1<8 \mathrm{~h}$ after their last meal.

Participants answered one question on past-year vigorous physical activity resulting in sweating or shortness of breath (none, $<1,1-2$ or $\geq 3 \mathrm{~h} /$ week). This variable was treated as a categorical variable with none as the reference.

Participants were classified as either non-smokers, former smokers or current smokers with non-smokers as the reference.

\section{Outcome}

The study endpoints were incident (first time) hospitalisation with CHD (ICD9 codes 410-414 and ICD10 codes I20-I25) as primary or secondary diagnosis or death with CHD as the underlying cause of death. Participants were followed from baseline through 31 December 2009 for CHD events through the Cardiovascular Disease in Norway project (CVDNOR, http://www.cvdnor.no) $)^{(27,28)}$ and The Cause of Death Registry. There were 107 non-fatal and five fatal episodes. Follow-up time was calculated as time from participation until CHD, death from other causes, emigration or 31 December 2009, whichever occurred first.

\section{Statistical analyses}

Descriptive characteristics include numbers with percentages and medians (25th, 75th percentiles) for categorical and continuous variables, respectively. Spearman's rank correlation (rho, $\rho$ ) was used to evaluate correlations between quartiles of carbohydrate intake and SFA intake with baseline characteristics. In addition, Spearman correlations of intake of carbohydrates with total fat and SFA were evaluated. To evaluate linear trends in baseline characteristics across quartiles of carbohydrate and SFA intakes as percentage of total energy intake, we used ordinal logistic regression for categorical outcome variables, logistic regression for dichotomous outcome variables and linear regression for continuous outcome variables where median intake as $\mathrm{E} \%$ within each quartile group was used as the independent variable in the analyses. Cox proportional hazard models were used to calculate adjusted hazard ratios (HR) with $95 \% \mathrm{CI}$ for CHD associated with continuous and quartile intake of carbohydrates and SFA. The included covariates were potential confounders associated with the intake of carbohydrates and SFA and with CHD, which also modified the association of either SFA or carbohydrate with CHD when included in the multivariable model. Two primary analyses are presented: model 1 adjusted for age (continuous (years)), sex and total energy intake (continuous ( $\mathrm{kcal} / \mathrm{d})$ ); model 2 additionally adjusted for vigorous physical activity (none $v .<1 \mathrm{~h} /$ week, $1-2 \mathrm{~h} /$ week or $\geq 3 \mathrm{~h} /$ week) with none as the reference and smoking habits (non-smokers $v$. previous smokers and non-smokers $v$. current smokers). The following additional confounders were also evaluated, but inclusion of the variables did not materially alter the associations of SFA or carbohydrates with CHD: family history of myocardial infarction, educational level and alcohol intake (E\%). Further, carbohydrate analyses also evaluated consistency in results after adjustment for energy-adjusted fibre from bread, fruit and vegetables. SFA analyses were further adjusted for energy-adjusted intake of cholesterol, PUFA and protein.

Supplementary analyses evaluated models adjusted for age, sex and energy intake (model 1), with additional adjustments for HDL-cholesterol, LDL-cholesterol, TAG, glucose, systolic blood pressure, diastolic blood pressure and BMI (model 2); with additional adjustments for diabetes/prediabetes, hypertension, family history of myocardial infarction, statins, oral hypoglycaemics (including metformin) and insulin and anti-hypertensive medications (model 3) and with additional adjustments for smoking, physical activity, alcohol consumption in $\mathrm{E} \%$ and education (model 4) (see online supplementary material, Supplemental Table S1). To test for linear trends across intake quartiles, median intake as $\mathrm{E} \%$ within each quartile group was used as the independent variable. We also evaluated SFA from cheese and SFA when excluding the contribution from cheese for their associations with incident CHD. In additional supplementary analyses, we stratified intake of SFA on smoking habits (see online supplementary material, Supplemental Table S2) and we also evaluated associations between carbohydrates and SFA from other specific food groups and CHD risk (see online supplementary material, Supplemental Tables S3 and S4). Missing data were handled with listwise deletion.

The proportional hazard assumption was evaluated using Schoenfeld's test.

To evaluate the continuous association between exposure and outcome, and assess potential non-linear associations, smoothed penalised splines were plotted ${ }^{(29)}$.

We used theoretical substitution analyses to model the substitution of carbohydrates with $\mathrm{SFA}^{(30)}$. Variables for the $\mathrm{E} \%$ (per $5 \mathrm{E} \%$ unit increments) of all macronutrients except carbohydrates (SFA, monounsaturated fat, PUFA, protein and alcohol) were included in a Cox model with adjustment for total energy intake, age, sex, physical activity and smoking habits. The HR for SFA is then interpreted as the change in estimated risk for each $5 \mathrm{E} \%$ unit increase in SFA while holding all other variables in the model constant but allowing for concomitant decreases in carbohydrate intake as all sources of macronutrients sum to $100 \%$ of energy 
intake. The same approach was used to evaluate the theoretical substitution of carbohydrates with other macronutrients: total fat, protein and PUFA intake per $5 \mathrm{E} \%$ unit increase in a model with other macronutrients except carbohydrates $^{(30)}$.

Sensitivity analyses were conducted where we excluded the first 2 years of observation following the baseline assessment in all of the above analyses.

Statistical analyses were performed using Stata version 15 (StataCorp LP) and R version 3.4.0 (https://www.rproject.org/), The R Foundation for Statistical Computing. $P$-values $<0.05$ were considered statistically significant.

\section{Results}

\section{Characteristics of the study population}

At baseline, mean age was 48 (SD 0.7) years, median BMI was 24.9 (25th, 75th percentiles $22.8,27.4) \mathrm{kg} / \mathrm{m}^{2}, 33.5 \%$ smoked daily, $45.9 \%$ reported at least $1 \mathrm{~h}$ vigorous physical activity per week and $25.3 \%$ had indications of reduced metabolic health defined as having hypertension, prediabetes or diabetes. Intake of total fat ranged from 14 to $53 \mathrm{E} \%$ with a median intake of $33 \mathrm{E} \%$. Intake of total carbohydrates ranged from 21 to $74 \mathrm{E} \%$ with a median intake of $49 \mathrm{E} \%$. Less than 1 and $6 \%$ had an intake of carbohydrates at or below 30 and $40 \mathrm{E} \%$, respectively, while 3 and $<1 \%$ had an intake of carbohydrates at or above 60 and $70 \mathrm{E} \%$, respectively. Intake of protein ranged from 6 to $30 \mathrm{E} \%$ with a median intake of $16 \mathrm{E} \%$, while intake of SFA ranged from 4 to $25 \mathrm{E} \%$ with a median intake of $13 \mathrm{E} \%$. Less than $1 \%$ had an intake of SFA at or below $6 \mathrm{E} \%$, while $14 \%$ had an intake at or above $15 \mathrm{E} \%$.

During a mean $10 \cdot 8$ (SD 1.3) years of follow-up, representing 32449 person-years among 2995 participants (1282 men and 1713 women), we documented 112 incident CHD events. Due to missing values $(2 \cdot 1 \%$ for smoking habits and $3.8 \%$ for physical activity), multivariableadjusted analyses included 2820 participants (1224 men and 1596 women) and 105 CHD events. Sixty participants died due to other causes during follow-up. When evaluating Spearman correlations between carbohydrate quartiles and baseline characteristics, all correlations $(\rho)$ were between -0.2 and $<0 \cdot 1$. However, evaluation of baseline characteristics by quartiles of carbohydrate intake identified that the proportion of participants performing at least $1 \mathrm{~h}$ vigorous physical activity per week was higher in higher quartiles, while the proportions of men, daily smokers and participants with glucose intolerance were lower in higher quartiles (Table 1). Also, waist circumference, serum levels of TC, LDL-cholesterol and HDL-cholesterol were lower in higher carbohydrate quartile groups. Intakes of total fat, protein and alcohol were lower with higher quartiles of carbohydrate intake. Bread was the major contributor to carbohydrates in this population. While intake ( $\mathrm{g} / \mathrm{d}$ per $1000 \mathrm{kcal})$ of bread, sweetened beverages, juice, and fruit and berries (both fresh and canned/preserved) was higher with higher quartiles of carbohydrate intake, there were less noticeable differences for other carbohydrate sources across quartiles. Vegetable and fibre intakes (g/d per $1000 \mathrm{kcal})$, for example, were similar in the various carbohydrate intake quartiles (Table 1).

When evaluating Spearman correlations between SFA quartiles and the baseline characteristics, all rhos $(\rho)$ were between $-0 \cdot 1$ and $<0 \cdot 1$. However, the percentage daily smokers were higher with higher quartiles of SFA intake, while the percentage of participants who were men, performed at least $1 \mathrm{~h}$ vigorous physical activity per week or had hypertension was lower with higher quartiles (Table 2). Also, BMI, waist circumference and TAG levels, as well as the percentage taking medications for hypercholesterolaemia, were lower with higher SFA quartiles. While intake of cheese was higher with higher quartiles of SFA intake, there were less noticeable differences for other SFA sources across quartiles. Family history of myocardial infarction did not differ between quartiles of carbohydrate ( $\left.P_{\text {trend }} 0.95\right)$ or SFA $\left(P_{\text {trend }} 0 \cdot 23\right)$ intake as percentage of total energy.

\section{Associations between intake of carbobydrates and SFA and incident CHD}

Higher intake of carbohydrates was borderline significantly associated with higher risk of CHD in model 1 (adjusted for age, sex and energy intake) $\left(\mathrm{HR}_{\mathrm{Q}(q u a r t i l e}\right) 4 v$. Q1 $1.63,95 \% \mathrm{CI}$ 0.96, 2.76, $P_{\text {trend }}=0.056$ ) (Table 3). This association became stronger and significant after further adjustment for smoking habits and physical activity (model 2) $\left(\mathrm{HR}_{\mathrm{Q} 4} v\right.$. Q1 $2 \cdot 10,95 \%$ CI 1.22, 3.63, $\left.P_{\text {trend }}=0.003\right)$. Also, continuous analyses (per $2 \mathrm{E} \%$ ) showed significantly higher risk of CHD with higher intake of carbohydrates (HR 1.12, $95 \%$ CI 1.05, 1.20), after adjusting for age, sex, energy intake, smoking habits and physical activity. Further adjustments for intermediate factors, relevant medications and potential confounders did not materially influence the association (see online supplementary material, Supplemental Table S1).

Plotting the data adjusting for model 2 covariates indicated a linear relationship (Fig. 1(a)).

When examining the association between carbohydrates from various food items, we found no associations with risk of CHD (see online supplementary material, Supplemental Table S3).

A high intake of SFA was significantly associated with lower risk of CHD in the model adjusted for age, sex and energy intake (model 1) $\left(\mathrm{HR}_{\mathrm{Q} 4} v\right.$. Q1 $0.53,95 \%$ CI 0.32 , $\left.0.90, P_{\text {trend }}=0.013\right)$ (Table 3$)$. This association became stronger after further adjustment for smoking habits and physical activity (model 2$)\left(\mathrm{HR}_{\mathrm{Q} 4} v . \mathrm{Q}_{1} \quad 0.44,95 \% \mathrm{CI}\right.$ $\left.0 \cdot 26,0 \cdot 76, P_{\text {trend }}=0.002\right)$. Also, continuous analyses (per $2 \mathrm{E} \%$ ) showed significantly lower risk of CHD with higher intake of SFA (HR 0.78, $95 \%$ CI 0.66, 0.92), after adjusting 


\section{Nes Public Health Nutrition}

Table 1 Baseline characteristics by quartiles of carbohydrate intake (energy percentage (E\%)), The Hordaland Health Study*

\begin{tabular}{|c|c|c|c|c|c|c|c|c|c|c|c|}
\hline & \multicolumn{2}{|r|}{ Total } & \multicolumn{2}{|r|}{ Q1 } & \multicolumn{2}{|r|}{ Q2 } & \multicolumn{2}{|r|}{ Q3 } & \multicolumn{2}{|r|}{ Q4 } & \multirow[b]{2}{*}{$P_{\text {trend }} \dagger$} \\
\hline & $\begin{array}{l}\text { Median/ } \\
n\end{array}$ & $\begin{array}{l}\text { 25th, 75th } \\
\text { percentiles/\% }\end{array}$ & $\begin{array}{l}\text { Median/ } \\
n\end{array}$ & $\begin{array}{l}\text { 25th, 75th } \\
\text { percentiles/\% }\end{array}$ & $\begin{array}{l}\text { Median/ } \\
n\end{array}$ & $\begin{array}{c}\text { 25th, 75th } \\
\text { percentiles/\% }\end{array}$ & $\begin{array}{l}\text { Median/ } \\
n\end{array}$ & $\begin{array}{l}\text { 25th, } 75 \text { th } \\
\text { percentiles/\% }\end{array}$ & $\begin{array}{l}\text { Median/ } \\
n\end{array}$ & $\begin{array}{l}\text { 25th, 75th } \\
\text { percentiles/\% }\end{array}$ & \\
\hline Carbohydrates (E\%) & 49 & 46,53 & 43 & 40,44 & 48 & 47,48 & 51 & 50,52 & 56 & 54,58 & $<0.001$ \\
\hline $\begin{array}{l}\text { Carbohydrates (g/d per } 1000 \\
\text { kcal) }\end{array}$ & 123 & 114,132 & 107 & 101,110 & 119 & 116,121 & 127 & 125,129 & 139 & 135,145 & $<0.001$ \\
\hline Participants $(n)$ & 2995 & & 749 & & 749 & & 748 & & 749 & & \\
\hline Age (years) & 48 & 47,48 & 48 & 47,48 & 48 & 47,48 & 48 & 47,48 & 48 & 47,48 & 0.822 \\
\hline Men & 1282 & $42 \cdot 8$ & 348 & $46 \cdot 5$ & 332 & $44 \cdot 3$ & 320 & $42 \cdot 8$ & 282 & $37 \cdot 7$ & 0.001 \\
\hline $\begin{array}{l}\text { College and/or university } \\
\text { education }\end{array}$ & 1138 & $38 \cdot 3$ & 253 & $34 \cdot 0$ & 308 & 41.3 & 286 & $38 \cdot 4$ & 291 & 39.5 & 0.059 \\
\hline $\begin{array}{l}\text { Family history of infarction } \\
\text { Smoking habits }\end{array}$ & 1186 & $40 \cdot 9$ & 301 & $42 \cdot 0$ & 283 & $39 \cdot 0$ & 297 & $41 \cdot 0$ & 305 & $41 \cdot 7$ & $\begin{array}{r}0.952 \\
<0.001\end{array}$ \\
\hline Previous smokers & 915 & $31 \cdot 2$ & 218 & 29.5 & 225 & $30 \cdot 4$ & 240 & $32 \cdot 9$ & 232 & $32 \cdot 1$ & \\
\hline Current smokers & 982 & 33.5 & 337 & $45 \cdot 7$ & 268 & $36 \cdot 2$ & 203 & $27 \cdot 8$ & 174 & $24 \cdot 1$ & \\
\hline Physical activity & & & & & & & & & & & $<0.001$ \\
\hline None & 745 & $25 \cdot 9$ & 218 & $30 \cdot 0$ & 188 & $26 \cdot 0$ & 174 & $24 \cdot 1$ & 165 & $23 \cdot 3$ & \\
\hline$<1 \mathrm{~h} /$ week & 813 & $28 \cdot 2$ & 220 & $30 \cdot 2$ & 225 & $31 \cdot 2$ & 189 & $26 \cdot 2$ & 179 & $25 \cdot 3$ & \\
\hline $1-2 \mathrm{~h} /$ week & 908 & 31.5 & 189 & $26 \cdot 0$ & 232 & $32 \cdot 1$ & 246 & $34 \cdot 1$ & 241 & 34.0 & \\
\hline$\geq 3 \mathrm{~h} /$ week & 415 & 14.4 & 101 & $13 \cdot 9$ & 77 & $10 \cdot 7$ & 113 & $15 \cdot 7$ & 124 & $17 \cdot 5$ & \\
\hline Hypertension & 708 & $23 \cdot 7$ & 171 & $22 \cdot 9$ & 184 & $24 \cdot 6$ & 178 & $23 \cdot 8$ & 175 & $23 \cdot 4$ & 0.886 \\
\hline Glucose intolerance & & & & & & & & & & & 0.050 \\
\hline Pre-diabetes & 66 & $2 \cdot 2$ & 21 & $2 \cdot 8$ & 19 & $2 \cdot 6$ & 14 & 1.9 & 12 & $1 \cdot 6$ & \\
\hline Diabetes & 27 & 0.9 & 9 & $1 \cdot 2$ & 8 & $1 \cdot 1$ & 3 & 0.4 & 7 & 0.9 & \\
\hline Casual glucose $(\mathrm{mmol} / \mathrm{l}) \ddagger$ & $5 \cdot 01$ & $4.64,5.49$ & 5.04 & $4.69,5.50$ & 5.02 & $4.65,5.53$ & 5.01 & $4.64,5.45$ & 4.96 & $4.60,5.44$ & 0.094 \\
\hline BMI $\left(\mathrm{kg} / \mathrm{m}^{2}\right)$ & 24.9 & $22 \cdot 8,27 \cdot 4$ & $25 \cdot 0$ & $23 \cdot 0,27 \cdot 5$ & $24 \cdot 7$ & $22 \cdot 7,27 \cdot 2$ & 24.9 & $22 \cdot 7,27 \cdot 4$ & 24.9 & $22 \cdot 8,27 \cdot 4$ & 0.410 \\
\hline Waist circumference $(\mathrm{cm})$ & $85 \cdot 0$ & $77 \cdot 0,94 \cdot 0$ & $86 \cdot 0$ & $77 \cdot 0,95 \cdot 0$ & $85 \cdot 0$ & $76 \cdot 0,93 \cdot 0$ & $85 \cdot 0$ & $77 \cdot 0,93 \cdot 0$ & $84 \cdot 0$ & $76 \cdot 0,93 \cdot 0$ & 0.003 \\
\hline Cholesterol $(\mathrm{mmol} / \mathrm{l}) \ddagger$ & 5.65 & $5 \cdot 06,6 \cdot 30$ & $5 \cdot 72$ & $5 \cdot 13,6.45$ & 5.66 & $5.04,6 \cdot 28$ & 5.64 & $5 \cdot 04,6 \cdot 27$ & 5.57 & $5 \cdot 01,6 \cdot 22$ & 0.001 \\
\hline LDL-cholesterol (mmol/l)‡ & 3.57 & $3.01,4 \cdot 17$ & $3 \cdot 60$ & $3.03,4.27$ & 3.58 & $3.01,4.15$ & 3.57 & $3.02,4.18$ & 3.51 & $2.96,4.09$ & 0.010 \\
\hline HDL-cholesterol $(\mathrm{mmol} / \mathrm{l}) \ddagger$ & 1.28 & $1.06,1.53$ & 1.29 & $1.08,1.54$ & 1.29 & $1.05,1.55$ & $1 \cdot 28$ & $1.06,1.53$ & 1.26 & $1.03,1.51$ & 0.017 \\
\hline TAG $(\mathrm{mmol} / \mathrm{l}) \ddagger$ & 1.40 & $1.01,2.04$ & 1.42 & $1 \cdot 01,2 \cdot 1$ & 1.39 & $1.00,1.94$ & 1.37 & $1 \cdot 00,2 \cdot 01$ & 1.41 & $1 \cdot 02,2 \cdot 10$ & 0.933 \\
\hline \multicolumn{12}{|l|}{ Medications for } \\
\hline Diabetes & 14 & 0.5 & 4 & 0.5 & 4 & 0.5 & 2 & 0.3 & 4 & 0.5 & 0.842 \\
\hline Hypertension & 134 & 4.5 & 29 & 3.9 & 40 & $5 \cdot 3$ & 33 & 4.4 & 32 & 4.3 & 0.879 \\
\hline Hypercholesterolemia & 50 & 1.7 & 19 & 2.5 & 7 & 0.9 & 12 & 1.6 & 12 & 1.6 & 0.262 \\
\hline \multicolumn{12}{|l|}{ Dietary intake } \\
\hline SFA (E\%) & 13 & 11,14 & 14 & 13,16 & 13 & 12,14 & 12 & 11,13 & 11 & 9,12 & $<0.001$ \\
\hline Total fat (E\%) & 33 & 29,36 & 38 & 35,41 & 34 & 32,36 & 31 & 30,33 & 27 & 25,29 & $<0.001$ \\
\hline Protein (E\%) & 16 & 14,17 & 17 & 15,18 & 16 & 15,17 & 16 & 14,17 & 15 & 14,16 & $<0.001$ \\
\hline Alcohol (E\%) & 1 & 0,3 & 2 & 1,4 & 1 & 0,3 & 1 & 0,2 & 1 & 0,2 & $<0.001$ \\
\hline $\begin{array}{l}\text { Cholesterol (mg/d per } \\
1000 \mathrm{kcal})\end{array}$ & 130 & 110,152 & 152 & 131,176 & 137 & 119,156 & 126 & 111,142 & 107 & 91,125 & $<0.001$ \\
\hline Fibre (g/d per $1000 \mathrm{kcal})$ & 11 & 10,13 & 10 & 9,11 & 11 & 10,12 & 12 & 10,14 & 13 & 11,16 & $<0.001$ \\
\hline Energy intake (kcal§/d) & 2057 & 1690,2550 & 2133 & 1751,2654 & 2128 & 1750,2578 & 2079 & 1687,2561 & 1917 & 1559, 2399 & $<0.001$ \\
\hline
\end{tabular}




\section{NSyblic Health Nutrition}

\begin{tabular}{|c|c|c|c|c|c|c|c|c|c|c|c|}
\hline & \multicolumn{2}{|r|}{ Total } & \multicolumn{2}{|r|}{ Q1 } & \multicolumn{2}{|r|}{ Q2 } & \multicolumn{2}{|r|}{ Q3 } & \multicolumn{2}{|r|}{ Q4 } & \multirow[b]{2}{*}{$P_{\text {trend }}$} \\
\hline & $\begin{array}{c}\text { Median/ } \\
n\end{array}$ & $\begin{array}{c}\text { 25th, } 75 \text { th } \\
\text { percentiles/\% }\end{array}$ & $\begin{array}{c}\text { Median/ } \\
n\end{array}$ & $\begin{array}{c}\text { 25th, } 75 \text { th } \\
\text { percentiles/\% }\end{array}$ & $\begin{array}{c}\text { Median/ } \\
n\end{array}$ & $\begin{array}{c}\text { 25th, } 75 \text { th } \\
\text { percentiles/\% }\end{array}$ & $\begin{array}{c}\text { Median/ } \\
n\end{array}$ & $\begin{array}{c}25 \text { th, } 75 \text { th } \\
\text { percentiles/\% }\end{array}$ & $\begin{array}{c}\text { Median/ } \\
n\end{array}$ & $\begin{array}{c}\text { 25th, } 75 \text { th } \\
\text { percentiles/\% }\end{array}$ & \\
\hline \multicolumn{12}{|l|}{ Intake of food items } \\
\hline \multicolumn{12}{|l|}{ Cakes } \\
\hline g/d per $1000 \mathrm{kcal}$ & 10 & 5,17 & 8 & 3,14 & 11 & 5,18 & 11 & 6,18 & 10 & 5,16 & 0.00 \\
\hline E\% carbohydrates & 1.5 & $0 \cdot 7,2 \cdot 6$ & $1 \cdot 2$ & $0.5,2 \cdot 1$ & 1.6 & $0.7,2.6$ & 1.6 & $0.9,2.8$ & 1.5 & $0.7,2 \cdot 6$ & $<0.00$ \\
\hline \multicolumn{12}{|l|}{ Snacks } \\
\hline g/d per $1000 \mathrm{kcal}$ & 2 & 1,5 & 3 & 1,6 & 2 & 1,5 & 2 & 1,4 & 1 & 0,4 & $<0.00$ \\
\hline E\% carbohydrates & 0.3 & $0.1,0.7$ & 0.4 & $0.1,0.8$ & 0.3 & $0.1,0.7$ & 0.3 & $0.1,0.7$ & 0.2 & $0,0.6$ & $<0.00$ \\
\hline \multicolumn{12}{|l|}{ Soft drinks with sugar } \\
\hline $\mathrm{g} / \mathrm{d}$ per $1000 \mathrm{kcal}$ & 25 & 0,65 & 18 & 0,43 & 28 & 2,68 & 27 & 2,63 & 34 & 1,86 & $<0.00$ \\
\hline E\% carbohydrates & 1.0 & $0,2 \cdot 6$ & 0.7 & $0,1 \cdot 7$ & $1 \cdot 1$ & $0 \cdot 1,2 \cdot 8$ & $1 \cdot 1$ & $0 \cdot 1,2 \cdot 6$ & 1.4 & $0.0,3.6$ & $<0.00$ \\
\hline \multicolumn{12}{|l|}{ Fresh fruit and berries } \\
\hline $\mathrm{g} / \mathrm{d}$ per $1000 \mathrm{kcal}$ & 62 & 35,98 & 43 & 24,71 & 59 & 35,91 & 66 & 42,104 & 85 & 48,139 & $<0.00$ \\
\hline E\% carbohydrates & 3.3 & $1 \cdot 9,5 \cdot 3$ & $2 \cdot 3$ & $1 \cdot 3,3 \cdot 7$ & $3 \cdot 2$ & $1 \cdot 9,4 \cdot 8$ & 3.6 & $2 \cdot 2,5 \cdot 6$ & 4.5 & $2 \cdot 6,7 \cdot 5$ & $<0.00$ \\
\hline \multicolumn{12}{|l|}{ Juice } \\
\hline g/d per $1000 \mathrm{kcal}$ & 20 & 2, 49 & 12 & 0,32 & 21 & 4, 48 & 26 & 6,58 & 23 & 2,63 & $<0.00$ \\
\hline $\mathrm{E} \%$ carbohydrates & 0.8 & $0 \cdot 1,2 \cdot 0$ & 0.5 & $0,1 \cdot 3$ & 0.8 & $0.2,1.9$ & 1.0 & $0.2,2.3$ & 0.9 & $0.1,2.5$ & $<0.00$ \\
\hline \multicolumn{12}{|c|}{ Conserved fruit and berries } \\
\hline $\mathrm{g} / \mathrm{d}$ per $1000 \mathrm{kcal}$ & 13 & 3,25 & 7 & 1,18 & 13 & 4,24 & 16 & 6,28 & 17 & 5,32 & $<0.00$ \\
\hline E\% carbohydrates & $2 \cdot 3$ & $0.4,4.8$ & 1.0 & $0,3.4$ & $2 \cdot 3$ & $0.5,4.4$ & 2.9 & $0.9,5.3$ & 3.1 & $0 \cdot 7,6 \cdot 1$ & $<0.00$ \\
\hline \multicolumn{12}{|l|}{ Bread } \\
\hline g/d per $1000 \mathrm{kcal}$ & 85 & 69,105 & 77 & 60,93 & 83 & 67,99 & 88 & 72,108 & 98 & 78,120 & $<0.00$ \\
\hline E\% carbohydrates & $16 \cdot 4$ & $13 \cdot 2,20 \cdot 1$ & 14.7 & $11 \cdot 7,17 \cdot 8$ & $15 \cdot 8$ & $13.0,18.9$ & $16 \cdot 8$ & $13 \cdot 8,20 \cdot 7$ & $18 \cdot 7$ & $14 \cdot 8,22 \cdot 9$ & $<0.00$ \\
\hline \multicolumn{12}{|c|}{ Rice, pasta, flour, cereals } \\
\hline $\mathrm{g} / \mathrm{d}$ per $1000 \mathrm{kcal}$ & 19 & 12,28 & 16 & 10,23 & 19 & 12,26 & 20 & 13,29 & 21 & 13, 33 & $<0.00$ \\
\hline E\% carbohydrates & 3.7 & $2 \cdot 3,5 \cdot 9$ & 3.0 & $2 \cdot 0,4 \cdot 6$ & 3.6 & $2 \cdot 3,5 \cdot 5$ & $4 \cdot 1$ & $2 \cdot 6,6 \cdot 4$ & 4.5 & $2 \cdot 6,7 \cdot 3$ & $<0.00$ \\
\hline \multicolumn{12}{|l|}{ Potatoes } \\
\hline g/d per $1000 \mathrm{kcal}$ & 48 & 32,67 & 47 & 30,63 & 47 & 33,64 & 48 & 31,67 & 52 & 33,71 & $<0.00$ \\
\hline E\% carbohydrates & $4 \cdot 1$ & $2 \cdot 7,5 \cdot 6$ & $4 \cdot 0$ & $2 \cdot 6,5 \cdot 4$ & $4 \cdot 1$ & $2 \cdot 9,5.5$ & $4 \cdot 1$ & $2 \cdot 7,5 \cdot 6$ & 4.3 & $2 \cdot 8,5 \cdot 8$ & $<0.00$ \\
\hline \multicolumn{12}{|l|}{ Vegetables } \\
\hline $\mathrm{g} / \mathrm{d}$ per $1000 \mathrm{kcal}$ & 85 & 54,131 & 82 & 53,122 & 85 & 55,129 & 88 & 57,132 & 87 & 52,136 & 0.13 \\
\hline E\% carbohydrates & $2 \cdot 2$ & $1 \cdot 5,3 \cdot 2$ & $2 \cdot 2$ & $1 \cdot 4,3 \cdot 1$ & $2 \cdot 2$ & $1 \cdot 5,3 \cdot 2$ & 2.3 & $1 \cdot 5,3 \cdot 2$ & $2 \cdot 3$ & $1.4,3.3$ & 0.03 \\
\hline
\end{tabular}

Q quartile.

*Values are presented as $n$ and $\%$ and median $(25$ th, 75 th percentiles) for categorical and continuous variables, respectively

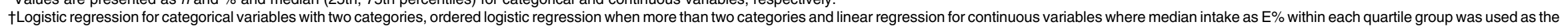
independent variable in the analyses.

łln serum.
§To convert kcal to kJ, multiply by 4.184. 
for age, sex, energy intake, smoking habits and physical activity. Further adjustments for intermediate factors, relevant medications and potential confounders did not materially influence the association (see online supplementary material, Supplemental Table S1).

Figure 1(b) illustrates lower risk of CHD with a higher intake of SFA until an intake of about $13 \mathrm{E} \%$, after which the curve levelled off, after adjustment for model 2 variables.

When stratifying on smoking habits, there was a tendency of lower risk of CHD with higher intake of SFA in all groups, but less so among current smokers (see online supplementary material, Supplemental Table S2).

When examining the association between SFA from various food items, we found that only SFA from cheese was significantly associated with a lower risk of CHD (Table 3). The median intake of SFA from cheese ranged from $0.5 \mathrm{E} \%(\mathrm{Q} 1)$ to $4.1 \mathrm{E} \%$ (Q4). After adjustments for age, sex, energy intake, physical activity and smoking habits (model 2), SFA from cheese was significantly associated with lower risk of CHD in the quartile analyses $\left(\mathrm{HR}_{\mathrm{Q} 4} v\right.$. Q1 $0.44,95 \%$ CI $0.24,0.83, P_{\text {trend }}=0.006$ ). Results from the evaluation of SFA from cheese as a continuous variable (per $1 \mathrm{E} \%$ ) were similar.

We further evaluated the association between SFA and CHD after excluding the SFA contribution from cheese, and in the quartile analyses, we found that intake of SFA after exclusion of cheese was associated with lower risk of CHD $\left(\mathrm{HR}_{\mathrm{Q} 4} v \cdot \mathrm{Q} 10.58,95 \%\right.$ CI 0.34, 0.98, $\left.P_{\text {trend }}=0.030\right)$, after adjustment for age, sex, energy intake, physical activity and smoking habits (model 2, Table 3). Results from the continuous analyses were in the same direction as the quartile analyses. Upon further evaluation (Fig. 1(c)), we observed deviations from linearity in the association between SFA intake and CHD risk after excluding SFA from cheese.

Higher intake of total carbohydrates correlated significantly with lower intake of SFA $(\rho=-0 \cdot 6, P<0.001)$ and lower intake of total fat $(\rho=-0 \cdot 8, P<0.001)$. Results from the theoretical substitution analyses are shown in Fig. 2. Substitution of $5 \%$ of total energy intake from carbohydrates with SFA was associated with a $26 \%$ lower risk of CHD (model 2 HR 0.74, 95 \% CI 0.40, 1.36), although not statistically significant. A substitution of carbohydrates with total fat was also associated with lower risk of CHD (model 2 HR 0.75, $95 \%$ CI 0.62, 0.90). To further evaluate whether substitution analyses of carbohydrates with SFA or with total fat could be attributed to an underlying beneficial effect of PUFA, we evaluated results of analyses substituting carbohydrates with PUFA in which we found a nonsignificant association with incident CHD (model $2 \mathrm{HR}$ $1 \cdot 42,95 \%$ CI 0.82, 2.47). Further, the substitution of carbohydrates with protein was not associated with the risk of CHD (model 2 HR 1.09, 95 \% CI 0.71, 1.68). When adjusting for age, sex and energy intake only, results of all substitution models were in the same direction as in the fully adjusted model, but were non-significant.
Exclusion of events occurring during the first 2 years of follow-up yielded no material differences in results.

\section{Discussion}

In this community-based study population, high intake of carbohydrates and low intake of SFA were associated with higher risk of incident CHD. Intake of SFA from cheese was significantly associated with lower CHD risk. When evaluating SFA intake after excluding the contribution of SFA from cheese, the association became weaker, but remained significant. Substituting $5 \%$ of total energy intake from carbohydrates with SFA and total fat was associated with lower CHD risk (HR of 0.74 and 0.75 , respectively), but was statistically significant only for total fat. The lack of a statistically significant finding for SFA may reflect, in part, the narrower range of SFA intake compared with total fat and carbohydrate intake.

Carbohydrates reflect a variety of sources including sucrose, fructose and refined cereals, as well as fibre-rich whole grains, vegetables and legumes. Refined carbohydrates and added sugar accounted for a large part of carbohydrate intake in the Norwegian diet at the time of HUSK baseline in 1997-1999 $9^{(5)}$. Even today, few Norwegians comply with the Nordic nutrition recommendations for fibre intake ${ }^{(31,32)}$. Per capita sales data indicate that intake of sugar-containing foods and beverages peaked at the end of the $1990 \mathrm{~s}^{(5)}$. In addition, a nationwide diet survey among men and women 16-79 years of age (1997-1999) found that their diet contained inadequate amounts of food products rich in fibre and that the intake of added sugar was 10 and $9 \mathrm{E} \%$ among men and women, respectively ${ }^{(33)}$. When evaluating baseline characteristics in this cohort, the intake of fruit and berries, sugar-sweetened beverages and juice doubled from the lowest to the highest quartile of carbohydrate intake. In contrast, intake of rice, pasta, flour and cereals was only modestly higher and vegetable intake did not differ across quartiles of total carbohydrate intake. Also, while recommended intake of fibre is $\geq 25 \mathrm{~g} / \mathrm{d}$ in women and $\geq 35 \mathrm{~g} / \mathrm{d}$ in $\operatorname{men}^{(31)}$, the median intake of fibre in the total study population was $24 \mathrm{~g} / \mathrm{d}$ and the median fibre intake in the highest quartile of carbohydrate intake was $26 \mathrm{~g} / \mathrm{d}$. However, FFQ are affected by systematic errors and do not precisely estimate dietary intake; therefore, these data should be interpreted with caution.

Previous cohort studies and meta-analyses have shown diverse results regarding the association between intake of carbohydrates and CHD when evaluating total carbohydrates. A study of men and women 30-59 years of age found that carbohydrate intake was associated with a lower CHD mortality risk (RR 0.96, $95 \%$ CI 0.94, 0.99) ${ }^{(34)}$. However, a large cohort study of individuals aged 35-70 years found that higher carbohydrate intake was not associated with the risk of CVD (HR 1.01, $95 \%$ CI 0.88, 1.15) or myocardial infarction (HR 0.90, $95 \%$ CI 0.73, 1.10) ${ }^{(23)}$. Carbohydrate intake was not consistently associated with CHD when 
Nublic Health Nutrition

Table 2 Baseline characteristics by quartiles of saturated fat intake (energy percentage (E\%)), The Hordaland Health Study*

\begin{tabular}{|c|c|c|c|c|c|c|c|c|c|c|c|}
\hline & \multicolumn{2}{|c|}{ Total } & \multicolumn{2}{|c|}{ Q1 } & \multicolumn{2}{|c|}{ Q2 } & \multicolumn{2}{|c|}{ Q3 } & \multicolumn{2}{|c|}{ Q4 } & \multirow[b]{2}{*}{$P_{\text {trend }} \dagger$} \\
\hline & Median/n & $\begin{array}{l}\text { 25th, 75th } \\
\text { percentiles/\% }\end{array}$ & Median/n & $\begin{array}{l}\text { 25th, 75th } \\
\text { percentiles/\% }\end{array}$ & Median/n & $\begin{array}{c}\text { 25th, 75th } \\
\text { percentiles/\% }\end{array}$ & Median/n & $\begin{array}{c}\text { 25th, 75th } \\
\text { percentiles/\% }\end{array}$ & Median/n & $\begin{array}{c}\text { 25th, 75th } \\
\text { percentiles/\% }\end{array}$ & \\
\hline SFA (E\%) & 13 & 11,14 & 10 & 9,11 & 12 & 11,12 & 13 & 13,14 & 15 & 15,16 & $<0.001$ \\
\hline SFA (g/d per $1000 \mathrm{kcal})$ & 14 & 12,16 & 11 & 10,12 & 13 & 13,14 & 15 & 14,15 & 17 & 16,18 & $<0.001$ \\
\hline Participants $(n)$ & 2995 & & 749 & & 749 & & 748 & & 749 & & \\
\hline Age (years) & 48 & 47,48 & 48 & 48,49 & 48 & 47,48 & 48 & 47,48 & 48 & 47,48 & 0.151 \\
\hline Men & 1282 & $42 \cdot 8$ & 327 & $43 \cdot 7$ & 349 & $46 \cdot 6$ & 318 & 42.5 & 288 & 38.5 & 0.016 \\
\hline College and/or university education & 1138 & $38 \cdot 3$ & 291 & 39.4 & 281 & $37 \cdot 6$ & 290 & 39.2 & 276 & $37 \cdot 0$ & 0.121 \\
\hline $\begin{array}{l}\text { Family history of infarction } \\
\text { Smoking habits }\end{array}$ & 1186 & $40 \cdot 9$ & 316 & $43 \cdot 4$ & 295 & $40 \cdot 7$ & 284 & $39 \cdot 2$ & 291 & $40 \cdot 5$ & $\begin{array}{r}0.227 \\
<0.001\end{array}$ \\
\hline Previous smoker & 915 & $31 \cdot 2$ & 248 & $34 \cdot 2$ & 241 & $32 \cdot 9$ & 230 & $31 \cdot 2$ & 196 & $26 \cdot 7$ & \\
\hline Current smoker & 982 & 33.5 & 197 & $27 \cdot 2$ & 233 & 31.8 & 259 & $35 \cdot 1$ & 293 & 39.9 & \\
\hline Physical activity & & & & & & & & & & & $<0.001$ \\
\hline None & 745 & $25 \cdot 9$ & 150 & $21 \cdot 0$ & 196 & $27 \cdot 3$ & 199 & $27 \cdot 4$ & 200 & $27 \cdot 7$ & \\
\hline$<1 \mathrm{~h} /$ week & 813 & 28.2 & 192 & $26 \cdot 9$ & 168 & $23 \cdot 4$ & 221 & 30.4 & 232 & $32 \cdot 2$ & \\
\hline 1-2 h/week & 908 & 31.5 & 241 & 33.7 & 243 & 33.8 & 221 & $30 \cdot 4$ & 203 & $28 \cdot 2$ & \\
\hline$\geq 3 \mathrm{~h} /$ week & 415 & 14.4 & 132 & 18.5 & 112 & $15 \cdot 6$ & 85 & $11 \cdot 7$ & 86 & 11.9 & \\
\hline Hypertension & 708 & 23.7 & 196 & $26 \cdot 2$ & 183 & 24.4 & 179 & 24.0 & 150 & $20 \cdot 0$ & 0.006 \\
\hline Glucose intolerance & & & & & & & & & & & 0.296 \\
\hline Pre-diabetes & 66 & $2 \cdot 2$ & 15 & $2 \cdot 0$ & 17 & $2 \cdot 3$ & 11 & 1.5 & 23 & $3 \cdot 1$ & \\
\hline Diabetes & 27 & 0.9 & 6 & 0.8 & 6 & 0.8 & 9 & $1 \cdot 2$ & 6 & 0.8 & \\
\hline Casual glucose $(\mathrm{mmol} / \mathrm{l}) \ddagger$ & $5 \cdot 01$ & $4 \cdot 64,5.49$ & 5.04 & $4 \cdot 66,5 \cdot 51$ & $5 \cdot 01$ & $4.66,5.47$ & 4.99 & $4.65,5.49$ & 4.98 & $4.60,5.43$ & 0.400 \\
\hline BMI $\left(\mathrm{kg} / \mathrm{m}^{2}\right)$ & 24.9 & $22 \cdot 8,27 \cdot 4$ & $25 \cdot 2$ & $23 \cdot 0,27 \cdot 6$ & $25 \cdot 2$ & $23 \cdot 0,27 \cdot 5$ & $24 \cdot 8$ & $23 \cdot 0,27 \cdot 4$ & 24.6 & $22 \cdot 2,27 \cdot 1$ & 0.002 \\
\hline Waist circumference $(\mathrm{cm})$ & $85 \cdot 0$ & $77 \cdot 0,94 \cdot 0$ & 85.0 & $77 \cdot 0,94.0$ & 86.0 & $78 \cdot 0,94.0$ & 85.0 & $77 \cdot 0,93 \cdot 0$ & 84.0 & $75 \cdot 0,93 \cdot 0$ & 0.021 \\
\hline Cholesterol $(\mathrm{mmol} / \mathrm{l}) \ddagger$ & 5.65 & $5.06,6.30$ & $5 \cdot 64$ & $5.06,6.35$ & $5 \cdot 61$ & $5 \cdot 01,6 \cdot 26$ & 5.69 & $5 \cdot 10,6 \cdot 28$ & 5.65 & $5.08,6.35$ & 0.729 \\
\hline LDL-cholesterol $(\mathrm{mmol} / \mathrm{l}) \ddagger$ & 3.57 & $3.01,4.17$ & 3.55 & $2 \cdot 96,4.17$ & 3.53 & $2 \cdot 99,4.11$ & 3.58 & $3.07,4 \cdot 17$ & $3 \cdot 61$ & $3.02,4.23$ & 0.250 \\
\hline HDL-cholesterol ( $\mathrm{mmol} / / \neq$ & 1.28 & $1.06,1.53$ & 1.29 & $1.06,1.53$ & 1.25 & $1.04,1.50$ & 1.29 & $1.07,1.54$ & 1.32 & $1.08,1.57$ & 0.064 \\
\hline TAG $(\mathrm{mmol} / \mathrm{l}) \ddagger$ & 1.40 & $1.01,2.04$ & 1.41 & $1.04,2.15$ & 1.47 & $1.03,2.08$ & 1.40 & $1.01,1.99$ & 1.33 & $0.95,1.93$ & 0.005 \\
\hline \multicolumn{12}{|l|}{ Medications for } \\
\hline Diabetes & 14 & 0.5 & 3 & 0.4 & 2 & 0.3 & 6 & 0.8 & 3 & 0.4 & 0.704 \\
\hline Hypertension & 134 & 4.5 & 36 & $4 \cdot 8$ & 37 & 4.9 & 33 & 4.4 & 28 & 3.7 & 0.270 \\
\hline Hypercholesterolaemia & 50 & $1 \cdot 7$ & 20 & $2 \cdot 7$ & 11 & 1.5 & 14 & 1.9 & 5 & 0.7 & 0.007 \\
\hline \multicolumn{12}{|l|}{ Dietary intake } \\
\hline Carbohydrates (E\%) & 49 & 46,53 & 54 & 51,58 & 51 & 48,53 & 48 & 45,51 & 45 & 42,48 & $<0.001$ \\
\hline Total fat $(\mathrm{E} \%)$ & 33 & 29,36 & 27 & 25,29 & 31 & 30,33 & 34 & 32,36 & 37 & 35,40 & $<0.001$ \\
\hline Protein (E\%) & 16 & 14,17 & 16 & 14,17 & 16 & 14,17 & 16 & 15,17 & 16 & 14,17 & 0.876 \\
\hline Alcohol (E\%) & 1 & 0,3 & 1 & 0,3 & 1 & 0,3 & 1 & 0,3 & 1 & 0,2 & $<0.001$ \\
\hline Cholesterol (mg/d per $1000 \mathrm{kcal})$ & 130 & 110,152 & 115 & 95,137 & 128 & 110,149 & 133 & 116,156 & 143 & 122,164 & $<0.001$ \\
\hline Fibre $(\mathrm{g} / \mathrm{d}$ per $1000 \mathrm{kcal})$ & 11 & 10,13 & 13 & 11,16 & 12 & 10,13 & 11 & 10,13 & 10 & 8,11 & $<0.001$ \\
\hline Energy intake $(\mathrm{kcal} \S / \mathrm{d})$ & 2057 & 1690,2550 & 1900 & 1537,2335 & 2093 & 1731,2584 & 2112 & 1712,2623 & 2182 & 1773,2584 & $<0.001$ \\
\hline
\end{tabular}




\section{$\mathbf{N S}$ "Public Cealth Nurrition}

Table 2 Continued

\begin{tabular}{|c|c|c|c|c|c|c|c|c|c|c|c|}
\hline & \multicolumn{2}{|c|}{ Total } & \multicolumn{2}{|c|}{ Q1 } & \multicolumn{2}{|c|}{ Q2 } & \multicolumn{2}{|c|}{ Q3 } & \multicolumn{2}{|c|}{ Q4 } & \multirow[b]{2}{*}{$P_{\text {trend }} \dagger$} \\
\hline & Median/n & $\begin{array}{c}\text { 25th, } 75 \text { th } \\
\text { percentiles/\% }\end{array}$ & Median/n & $\begin{array}{c}\text { 25th, } 75 \text { th } \\
\text { percentiles/\% }\end{array}$ & Median/n & $\begin{array}{c}\text { 25th, } 75 \text { th } \\
\text { percentiles/\% }\end{array}$ & Median/n & $\begin{array}{c}\text { 25th, } 75 \text { th } \\
\text { percentiles/\% }\end{array}$ & Median/n & $\begin{array}{c}\text { 25th, } 75 \text { th } \\
\text { percentiles/\% }\end{array}$ & \\
\hline \multicolumn{12}{|l|}{$\begin{array}{l}\text { Intake of food items } \\
\text { Butterl| }\end{array}$} \\
\hline $\mathrm{g} / \mathrm{d}$ per $1000 \mathrm{kcal}$ & 0 & 1 & 0 & 0 & 0 & 1 & 0 & 1 & 0 & 3 & $<0.001$ \\
\hline E\% SFA & 0 & 1 & 0 & 0 & 0 & 0 & 0 & 0 & 0 & 1 & $<0.001$ \\
\hline \multicolumn{12}{|l|}{ Cheese } \\
\hline $\mathrm{g} / \mathrm{d}$ per $1000 \mathrm{kcal}$ & 13 & 7,21 & 9 & 4,14 & 11 & 7,18 & 15 & 9,24 & 19 & 11,32 & $<0.001$ \\
\hline E\% SFA & 2 & 1,3 & 1 & 1,2 & 2 & 1,2 & 2 & 1,3 & 3 & 2,4 & $<0.001$ \\
\hline \multicolumn{12}{|l|}{ Margarine } \\
\hline $\mathrm{g} / \mathrm{d}$ per $1000 \mathrm{kcal}$ & 3 & 2,8 & 2 & 1,4 & 3 & 2,7 & 3 & 2,9 & 3 & 2,11 & $<0.001$ \\
\hline E\% SFA & 1 & 1,2 & 1 & 0,1 & 1 & 1,2 & 1 & 1,2 & 1 & 1,3 & $<0.001$ \\
\hline \multicolumn{12}{|l|}{ Milk and milk products } \\
\hline $\mathrm{g} / \mathrm{d}$ per $1000 \mathrm{kcal}$ & 129 & 65,205 & 131 & 61,214 & 140 & 71,213 & 128 & 69,196 & 119 & 61,196 & 0.031 \\
\hline $\mathrm{E} \%$ SFA & 1 & 1,2 & 1 & 1,2 & 1 & 1,2 & 1 & 1,2 & 2 & 1,3 & $<0.001$ \\
\hline \multicolumn{12}{|l|}{ Meat and meat products } \\
\hline $\mathrm{g} / \mathrm{d}$ per $1000 \mathrm{kcal}$ & 55 & 41,70 & 49 & 36,63 & 56 & 43,70 & 57 & 43,74 & 57 & 42,73 & $<0.001$ \\
\hline E\% SFA & 2 & 2,3 & 2 & 2,3 & 2 & 2,3 & 2 & 2,3 & 3 & 2,3 & $<0.001$ \\
\hline \multicolumn{12}{|l|}{ Minced meat products } \\
\hline $\mathrm{g} / \mathrm{d}$ per $1000 \mathrm{kcal}$ & 24 & 15,34 & 20 & 12,29 & 25 & 16,33 & 26 & 17,36 & 26 & 17,35 & $<0.001$ \\
\hline E\% SFA & 1 & 1,2 & 1 & 1,1 & 1 & 1,2 & 1 & 1,2 & 1 & 1,2 & $<0.001$ \\
\hline
\end{tabular}

Q, quartile.
$*$ Values are presented as $n$ and $\%$ and median and 25 th, 75 th percentiles for categorical and continuous variables, respectively.

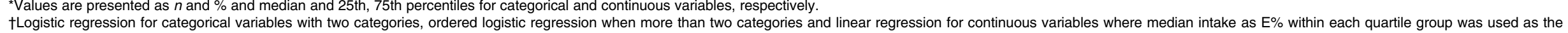
†Logistic regression for categorical va

fln serum.

§To convert kcal to kJ, multiply by 4.184.

IIIntake is reported as median and mean because of a large number of zero intake reporting. 
Table 3 Associations between macronutrients and risk of incident CHD, The Hordaland Health Study. Mean follow-up time $10 \cdot 8$ years

\begin{tabular}{|c|c|c|c|c|c|c|c|}
\hline \multirow[b]{2}{*}{ Intake of macronutrients (range in $\mathrm{E} \%)^{\star}$} & \multirow[b]{2}{*}{$n$} & \multicolumn{2}{|c|}{$\mathrm{CHD}$} & \multicolumn{2}{|c|}{ Model 1† } & \multicolumn{2}{|c|}{ Model 2‡ } \\
\hline & & $n$ & $\%$ & HR & $95 \% \mathrm{Cl}$ & HR & $95 \% \mathrm{Cl}$ \\
\hline Carbohydrates & 2995 & 112 & & & & & \\
\hline Q1 $(21,45)$ & 749 & 23 & $3 \cdot 1$ & 1 (ref) & & 1 (ref) & \\
\hline Q2 $(45,49)$ & 749 & 25 & 3.3 & 1.11 & $0.63,1.96$ & 1.09 & $0.60,1.98$ \\
\hline Q3 $(49,53)$ & 748 & 29 & 3.9 & 1.30 & $0.75,2.24$ & 1.67 & $0.96,2.89$ \\
\hline Q4 $(53,74)$ & 749 & 35 & 4.7 & 1.63 & $0.96,2.76$ & $2 \cdot 10$ & $1.22,3.63$ \\
\hline$P_{\text {trend }} \S$ & & & & 0.056 & & 0.003 & \\
\hline Continuous (per $2 \mathrm{E} \%$ ) & 2995 & 112 & & 1.08 & $1.01,1.15$ & $1 \cdot 12$ & $1 \cdot 05,1 \cdot 20$ \\
\hline Saturated fat & 2995 & 112 & & & & & \\
\hline Q1 $(4,11)$ & 749 & 44 & 5.9 & 1 (ref) & & 1 (ref) & \\
\hline Q2 $(11,13)$ & 749 & 24 & 3.2 & 0.55 & $0.34,0.91$ & 0.46 & $0.27,0.78$ \\
\hline Q3 $(13,14)$ & 748 & 23 & 3.1 & 0.55 & $0.33,0.92$ & 0.47 & $0.28,0.79$ \\
\hline Q4 $(14,25)$ & 749 & 21 & $2 \cdot 8$ & 0.53 & $0.32,0.90$ & 0.44 & $0.26,0.76$ \\
\hline$P_{\text {trend }} \S$ & & & & 0.013 & & 0.002 & \\
\hline Continuous (per 2 E\%) & 2995 & 112 & & 0.82 & $0.70,0.97$ & 0.78 & $0.66,0.92$ \\
\hline Saturated fat from cheese & 2995 & 112 & & & & & \\
\hline Q1 $(0,1)$ & 749 & 45 & $6 \cdot 0$ & 1 (ref) & & 1 (ref) & \\
\hline Q2 $(1,2)$ & 748 & 28 & 3.7 & 0.68 & $0.43,1.10$ & 0.78 & $0.49,1.27$ \\
\hline Q3 $(2,3)$ & 749 & 25 & 3.3 & 0.64 & $0.39,1.04$ & 0.60 & $0.35,1.03$ \\
\hline Q4 $(3,18)$ & 749 & 14 & 1.9 & 0.38 & $0.21,0.70$ & 0.44 & $0.24,0.83$ \\
\hline$P_{\text {trend }} \S$ & & & & 0.002 & & 0.006 & \\
\hline Continuous (per $1 \mathrm{E} \%$ ) & 2995 & 112 & & 0.84 & $0.74,0.97$ & 0.87 & $0.75,0.99$ \\
\hline Saturated fat after excluding saturated fat from cheese & 2995 & 112 & & & & & \\
\hline Q1 $(3,9)$ & 748 & 34 & 4.6 & 1 (ref) & & 1 (ref) & \\
\hline Q2 $(9,10)$ & 750 & 29 & 3.9 & 0.85 & $0.51,1.39$ & 0.71 & $0.42,1.20$ \\
\hline Q3 $(10,12)$ & 748 & 20 & $2 \cdot 7$ & 0.56 & $0.32,0.98$ & 0.46 & $0.26,0.81$ \\
\hline Q4 $(12,21)$ & 749 & 29 & 3.9 & 0.81 & $0.49,1.34$ & 0.58 & $0.34,0.98$ \\
\hline$P_{\text {trend }} \S$ & & & & 0.277 & & 0.030 & \\
\hline Continuous (per $2 \mathrm{E} \%$ ) & 2995 & 112 & & 0.94 & $0.79,1.12$ & 0.85 & $0.71,1.02$ \\
\hline
\end{tabular}

$\mathrm{E} \%$, energy percentage; $\mathrm{CHD}$, incident $\mathrm{CHD} ; n$, number of participants; $\mathrm{HR}$, hazard ratio; Q, quartile.

${ }^{*}$ Minimum and maximum intake of the macronutrient.

tCox proportional hazard regression analysis adjusted for age, sex and energy intake.

$\ddagger$ Adjusted in addition for physical activity and smoking habits.

$\S P_{\text {trend }}$, to test for linear trends across quartiles, we modelled the median intake of each quartile as a continuous variable.

(a)

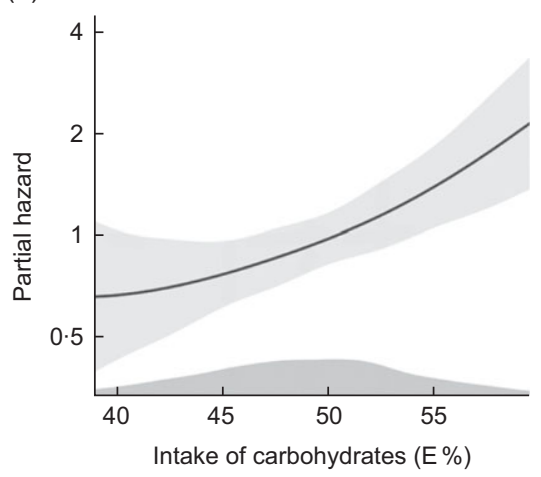

(b)

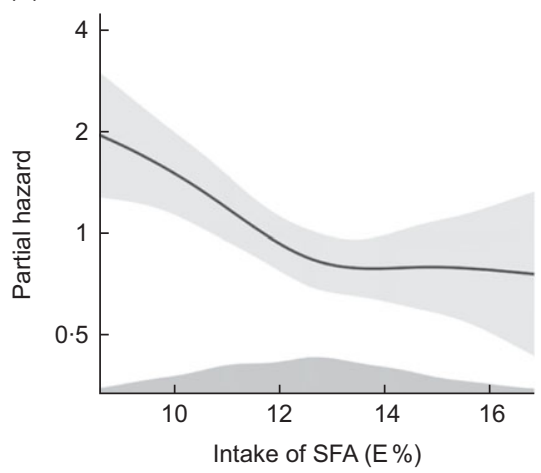

(c)

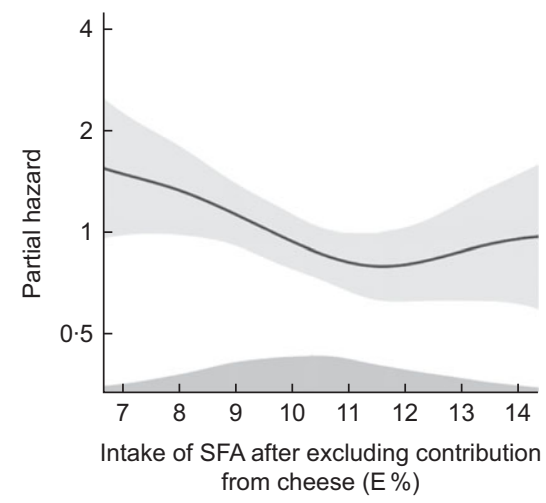

Fig. 1 Cox proportional hazards regression with penalized splines, The Hordaland Health Study. Distribution of partial hazard (black line) with $95 \% \mathrm{Cl}$ (shadow) for CHD across the distribution of a) intake of carbohydrates in $\mathrm{E} \%, \mathrm{~b}$ ) intake of saturated fatty acids (SFA) in $\mathrm{E} \%$ and $\mathrm{c}$ ) intake of SFA after excluding contribution from cheese in $\mathrm{E} \%$. The model includes age, sex, energy intake, physical activity and smoking habits. Intake above the $5^{\text {th }}$ th percentile and below the $95^{\text {th }}$ percentile is included in the figure

different sources of carbohydrates were considered separately. Li et $a l .{ }^{(35)}$ found in a cohort study that higher intake of carbohydrates from whole grains was associated with lower risk of incident CHD (HR 0.90, $95 \%$ CI 0.83, 0.98), while carbohydrates from refined starches/added sugars were positively associated with higher risk of CHD (HR 1.10, $95 \%$ CI 1.00, 1.21).
Fung et al. ${ }^{(36)}$ studied the association between consumption of sugar-sweetened beverages and the risk of CHD in the Nurses' Health Study and found that regular consumption of sugar-sweetened beverages was associated with a higher CHD risk. In addition, a meta-analysis of cohort studies reported that intake of sugar-sweetened beverages was associated with increased risk of myocardial 


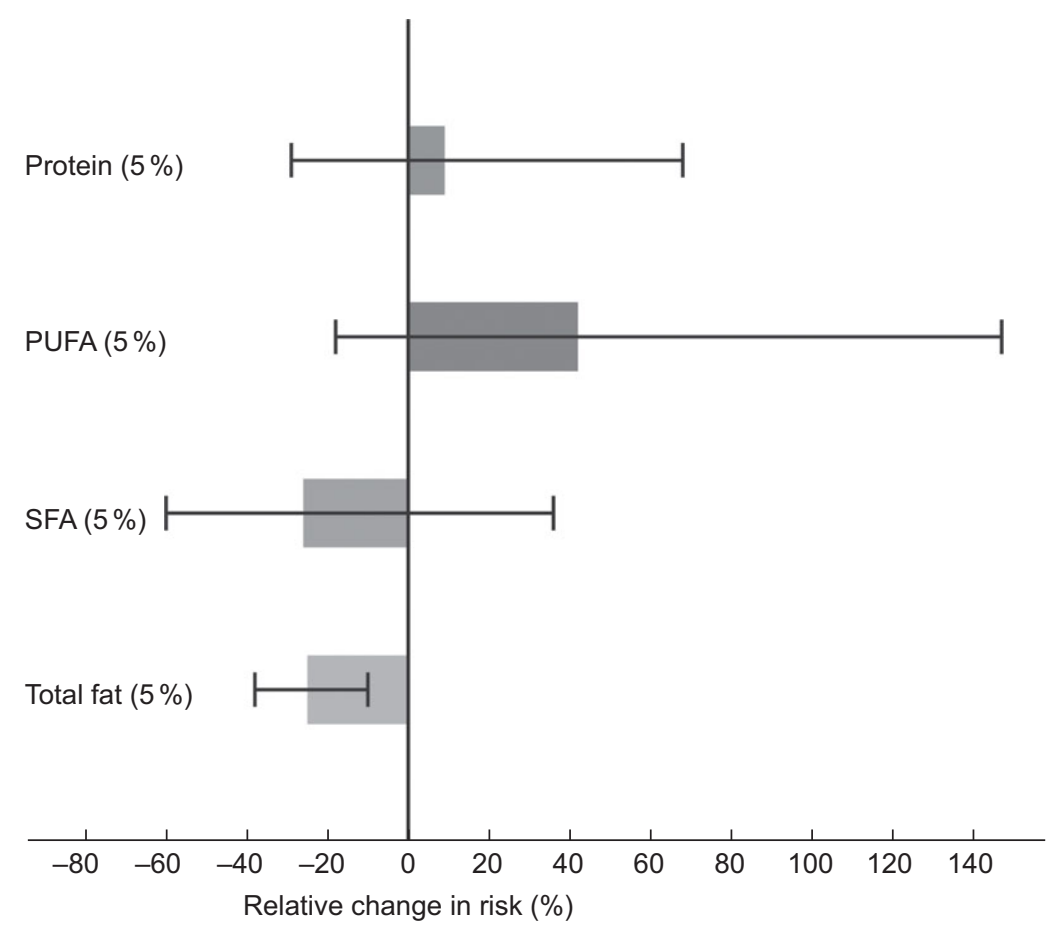

Fig. 2 Theoretical substitution analyses, illustrating an isocaloric substitution of $5 E \%$ from carbohydrates with total fat, saturated fatty acids (SFA), polyunsaturated fatty acids (PUFA) or protein and its association with CHD. Adjusted for age, sex, energy intake, physical activity and smoking habits. Mean 10.8 years follow-up of the Hordaland Health Study participants

infarction $^{(37)}$. In randomised controlled trials, dietary sugar intake has been found to increase blood pressure and serum TAG, TC and LDL-cholesterol ${ }^{(38)}$. While we did not identify any one particular source of carbohydrates to contribute to the overall carbohydrate association with CHD, we did note differences in the quality of carbohydrate sources between low to high carbohydrate intake quartiles where intake of fibre, vegetables and many carbohydrate sources remained essentially stable, while bread, sugar-sweetened beverages, juice, and preserved and fresh fruit and berries increased across the quartiles of carbohydrate intake. Thereby indicating that increased carbohydrate intake in the current study population represented increases in low-fibre and higher sucrose/fructose carbohydrates.

SFA intake in our study population came primarily from dairy products, especially cheese. The intake of cheese more than doubled from the lowest to the highest quartile of SFA intake, and cheese was also the main contributor to SFA intake in the highest quartile. As dairy products are important contributors of SFA, the general recommendation in Norway has been to reduce the intake of high-fat dairy products ${ }^{(39)}$. However, studies do not consistently support that this recommendation would reduce risk of $\mathrm{CHD}^{(40-42)}$. A systematic review and meta-analysis did not report a statistically significant association between total dairy intake and CHD (Summary RR 0.91, $95 \%$ CI $0.80,1.04)^{(41)}$. Further, the only dairy product significantly associated with lower CHD risk was cheese (Summary RR
0.82, $95 \%$ CI $0.72,0.93)^{(41)}$. In addition, Qin et al. ${ }^{(42)}$ reported no association between dairy intake and CHD (RR 0.94, $95 \%$ CI 0.82, 1.07), and CHD risk was lowered by cheese consumption also in this study (RR 0.84, $95 \%$ CI $0.71,1.00)$.

We found that intake of SFA from cheese was the only food source associated with a lower risk of CHD. Underlying mechanisms for a potential CHD protective effect of cheese may relate to (i) fermentation which may influence dairy fat's contribution to LDL-cholesterol ${ }^{(43)}$ and (ii) menaquinones (vitamin $\mathrm{K}_{2}$ ) which comes primarily from cheese in European diets ${ }^{(44)}$. Geleijnse et al. ${ }^{(45)}$ found that menaquinone intake was inversely associated with serum TC and aortic calcification and positively associated with serum HDL-cholesterol. Menaquinones transported together with SFA may, therefore, be associated with lower $\mathrm{CHD}$ risk. Also, as most cheeses are not homogenised, they still contain milk fat globule membranes. Rosqvist et al. ${ }^{(46)}$ reported that intake of milk fat enclosed by milk fat globule membranes did not impair the lipoprotein profile when compared with butter oil. When evaluating the association between SFA and CHD after excluding the contribution from cheese, intake of SFA was still associated with lower risk of $\mathrm{CHD}$. The penalised spline illustrates almost the same pattern as for total SFA, but with a tendency of higher risk at higher intakes.

A systematic review and meta-analysis found that when comparing the highest $v$. lowest intake of SFA, there was no association observed between SFA intake and CHD 
(RR 1.03, $95 \%$ CI 0.98, 1.07) ${ }^{(18)}$. Another meta-analysis of cohort studies found that the highest $v$. lowest quintile intake of SFA had a weak association with the risk of CHD (RR 1.06, $95 \%$ CI 0.95, 1.17) ${ }^{(19)}$. However, the quality of the documentation was regarded as very low, and in an analysis not adjusted for cardiovascular risk factors such as serum cholesterol, there was a significantly higher risk of CHD mortality comparing the highest $v$. lowest intake of SFA (RR 1.20, $95 \%$ CI 1.02, 1.41) ${ }^{(19)}$.

Our results differ from these meta-analyses and likely reflect that, in the current study population, cheese was the predominant contributor to SFA, there was a narrow range of median SFA intake in the four quartiles, and there was an inverse association between SFA and carbohydrate intake.

\section{Theoretical substitution analyses}

Analysing the effect of one nutrient when considering the nutrients it substitutes provides another means of understanding the observed associations ${ }^{(30)}$. Another study suggested that reducing the intake of carbohydrates from refined grains and added sugars may produce beneficial metabolic effects that may decrease the risk of $\mathrm{CHD}^{(22)}$. Jakobsen et al. ${ }^{(21)}$ showed that when substituting $5 \mathrm{E} \%$ from SFA by carbohydrates, there was no association with fatal CHD (RR 0.96, $95 \%$ CI 0.82, 1.13), but a statistically significant increase in the overall CHD risk (RR 1.07, $95 \%$ CI 1.01, 1.14). When separately evaluating carbohydrates with high and low glycaemic index, only a substitution of SFA with high glycaemic index carbohydrates was associated with a higher risk of myocardial infarction (HR 1.33, $95 \%$ CI 1.08, 1.64) ${ }^{(22)}$. Chen et al. ${ }^{(47)}$ evaluated the association between dairy fat and CHD in US adults and found no significant benefit of replacing dairy fat with the same energy intake from refined starch and added sugar. However, the substitution of $5 \%$ of energy from dairy fat by carbohydrates from whole grains was associated with a significantly lower risk of CHD (RR 0.66, $95 \%$ CI $0.62,0.70)$.

The tendency for a lower risk of CHD when replacing carbohydrates with total fat and SFA may reflect a combination of the beneficial association observed between cheese consumption and CHD as well as the deleterious association between low-fibre carbohydrate intake and CHD. Total fat and SFA intake in the context of high-cheese consumption may not be generalisable to total fat and SFA intake in a low-cheese consumption context.

\section{Strengths and limitations}

Strengths of our study include a community-based sample of men and women with a relatively long follow-up time. Only sixty participants died due to other reasons until 2009; therefore, there was minimal competing risk from other causes of death. Linkage to the CVDNOR project database assured as good as complete follow-up. Also, we had information on health status, medication use, health habits and history of CHD at baseline, enabling us to evaluate incident CHD. Further, the FFQ captured the major sources of carbohydrates and SFA expected in the current study population, and energy adjustment of the statistical models is a well-established approach for reducing the bias related to self-reported dietary data.

Theoretical substitution analyses were performed, modelling the substitution of carbohydrates with PUFA, SFA, protein and total fat. Another strength is the robustness of the results which were similar from model to model after various adjustments.

Limitations include the relatively small number of participants and events limiting stratified analyses and multivariable adjustments.

Another limitation is the lack of information on possible changes over time in diet, medications and other risk factors. Both dietary habits and food products have changed during the study period, due to the recommendations on reducing intake of SFA as the source of fat and increasing intake of whole grains as the source of carbohydrates ${ }^{(31,48)}$. Intake of cooking oil has tripled from the late 1990s to about 2013, and the consumption of vegetables also increased, while intake of margarine and sugar-containing food decreased according to per capita sales data ${ }^{(5)}$.

Blood samples were non-fasting. Since postprandial TAG remain elevated for several hours, and the Friedewald equation, used for the calculation of LDLcholesterol, assumes fasting TAG values, LDL-cholesterol may be underestimated ${ }^{(49)}$. Also, most reference values for serum lipids and glucose are established on fasting blood specimen.

Further, a common problem with FFQ is systematic under- or overreporting of nutrient and energy intake, limiting the estimation of absolute intake. However, the FFQ is well suited to rank participants by dietary intake for evaluation of associations with health endpoints ${ }^{(50)}$. Given that FFQ are not optimal for determining absolute nutrient intake, caution is required in the interpretation of the theoretical substitution models ${ }^{(51)}$.

There may also be other limitations. A large proportion (75\%) of the participants reported zero intake of butter, likely reflecting underreporting. Also, we did not have extensive information on carbohydrate quality particularly for bread due to lack of historical food recipes, lack of food label details and type of carbohydrate content for the recipes from the dietary database at the end of the 1990s.

Nevertheless, when we adjusted for estimated fibre from bread, vegetables and fruit intake, total carbohydrate intake remained a statistically significant predictor of higher CHD risk. Another limitation of the current study is that the results cannot be generalisable to populations with a greater range in carbohydrate or SFA intake. In the current study, the intake of SFA varied from 4 to $25 \mathrm{E} \%$ and the intake of carbohydrates varied from 21 to $74 \mathrm{E} \%$ resulting 
in a narrower range of intake when we evaluated the median intake between the lowest and highest quartiles (i.e., 10-15 E\% for SFA and 43-56 E\% for carbohydrates), precluding our ability to generalise to lower and higher intake values. The current study can therefore not be compared with previous studies that have shown higher allcause and cause-specific mortality associated with much lower carbohydrate intakes than our study population ${ }^{52,53)}$. Finally, the available data were not appropriate for studying unsaturated fat, given the changing trans-fatty acid composition of unsaturated fat during the study period.

While reverse causation is a general concern in observational studies of dietary habits and disease outcomes, we noted a similar percentage of participants with a family history of $\mathrm{CHD}$ and similar baseline BMI values across quartiles of carbohydrate and SFA intake. Further, adjusting for family history of CHD and BMI did not alter our findings. Although we performed multivariable analyses, residual confounding may still be present.

Lastly, it is of note that at the end of follow-up, participants' age was generally lower than the mean age of acute myocardial infarction in Norway which is 73.8 years for men and 79.1 years for women ${ }^{(54)}$. Thus, our findings may reflect mechanisms involved in early-onset CHD and may not necessarily be generalisable to older populations.

\section{Conclusion}

The focus of the current study was to evaluate the importance of the interplay between SFA and total carbohydrates, including SFA sources, when evaluating the association between SFA and CHD. A high intake of carbohydrates, reflecting low-fibre and relatively higher sucrose/fructose dietary sources, and a low intake of SFA were associated with higher CHD risk in the current study population. Substituting carbohydrates with total fat was associated with lower risk. Also, SFA from cheese was associated with lower risk of CHD.

Further research evaluating potential benefits of dairy products and their nutritional constituents is warranted. Also, there is a need to clarify the relative health trade-offs between replacing carbohydrate intake with fat intake in study populations with diverse dietary habits and a wider range in carbohydrate and SFA intakes. In addition, results of our study suggest that dietary guidelines development and their communication to the public, especially regarding reductions in certain foods and nutrients, need to consider the potential health impact of alternative sources of energy.

\section{Acknowledgements}

Acknowledgements: The authors thank Tomislav Dimoski at the Norwegian Institute of Public Health, Oslo, Norway for his contribution by developing the software necessary for obtaining data from Norwegian hospitals, including conducting the data collection and quality assurance. Financial support: No funding body has influenced data collection, analysis or its interpretations. University of Bergen supported this work. Funding for Open Access Publication. University of Bergen. Conflict of interest: On behalf of all authors, the corresponding author states that there is no conflict of interest. Authorship: G.S.T. and O.N. designed the study and collected the data. T.R.H., K.B. and J.I. undertook the statistical analyses. T.R.H. wrote the first draft of the manuscript and was responsible for the full submission process. All the authors refined the various versions of the full paper and approved the final manuscript. The corresponding author attests that all listed authors meet authorship criteria and that no others meeting the criteria have been omitted. Ethics of human subject participation: The current study was conducted according to the guidelines laid down in the Declaration of Helsinki, and all procedures involving study participants were approved by the Regional Committee for Medical and Health Research Ethics. Written informed consent was obtained from all subjects.

\section{Disclaimer}

The current study used data from the Norwegian Cause of Death Registry. The interpretation and reporting of these data are the sole responsibility of the authors, and no endorsement by the registry is intended nor should be inferred.

\section{Supplementary material}

For supplementary material accompanying this paper visit https://doi.org/10.1017/S1368980020003043

\section{References}

1. Keys A, Anderson JT \& Grande F (1957) Prediction of serumcholesterol responses of man to changes in fats in the diet. Lancet 273, 959-966.

2. Keys A, Menotti A, Karvonen MJ et al. (1986) The diet and 15 -year death rate in the seven countries study. Am J Epidemiol 124, 903-915.

3. Mensink RP \& Katan MB (1992) Effect of dietary fatty acids on serum lipids and lipoproteins. A meta-analysis of 27 trials. Arterioscler Thromb 12, 911-919.

4. Mozaffarian D (2016) Dietary and policy priorities for cardiovascular disease, diabetes, and obesity: a comprehensive review. Circulation 133, 187-225.

5. Bøe E, Svennerud M, Kirsanova E et al. (2015) Utvikling i norsk kosthold. Matforsyningsstatistikk og Forbruksundersøkelser (Development in the Norwegian Diet. Food Supply Statistics and Consumption Surveys). Oslo: Helsedirektoratet.

6. Cohen E, Cragg M, deFonseka J et al. (2015) Statistical review of US macronutrient consumption data, 1965-2011: Americans have been following dietary guidelines, coincident with the rise in obesity. Nutrition 31, 727-732.

7. The United States Department of Agriculture (USDA) Center for Nutrition Policy and Promotion (1992) The Food Guide Pyramid. Washington DC: Home and Garden Bulletin 252. 
8. Lennerz BS, Alsop DC, Holsen LM et al. (2013) Effects of dietary glycemic index on brain regions related to reward and craving in men. Am J Clin Nutr 98, 641-647.

9. Odegaard AO, Choh AC, Czerwinski ST et al. (2012) Sugarsweetened and diet beverages in relation to visceral adipose tissue. Obesity (Silver Spring) 20, 689-691.

10. Ebbeling CB, Swain JF, Feldman HA et al. (2012) Effects of dietary composition on energy expenditure during weightloss maintenance. JAMA 307, 2627-2634.

11. Ludwig DS, Willett WC, Volek JS et al. (2018) Dietary fat: from foe to friend? Science 362, 764-770.

12. Mansoor N, Vinknes KJ, Veierød MB et al. (2016) Effects of low-carbohydrate diets v. low-fat diets on body weight and cardiovascular risk factors: a meta-analysis of randomised controlled trials. Br J Nutr 115, 466-479.

13. Volek JS, Fernandez ML, Feinman RD et al. (2008) Dietary carbohydrate restriction induces a unique metabolic state positively affecting atherogenic dyslipidemia, fatty acid partitioning, and metabolic syndrome. Prog Lipid Res $\mathbf{4 7}$, 307-318.

14. Volek JS, Phinney SD, Forsythe CE et al. (2009) Carbohydrate restriction has a more favorable impact on the metabolic syndrome than a low fat diet. Lipids 44, 297-309.

15. Hall KD, Bemis T, Brychta R et al. (2015) Calorie for calorie, dietary fat restriction results in more body fat loss than carbohydrate restriction in people with obesity. Cell Metab 22, 427-436.

16. Hu S, Wang L, Yang D et al. (2018) Dietary fat, but not protein or carbohydrate, regulates energy intake and causes adiposity in mice. Cell Metabol 28, 415-431.

17. Schwab U, Lauritzen L, Tholstrup T et al. (2014) Effects of the amount and type of dietary fat on cardiometabolic risk factors and risk of developing type 2 diabetes, cardiovascular disease, and cancer: systematic review. Food Nutr Res 58, 25145.

18. Chowdhury R, Warnakula S, Kunutsor S et al. (2014) Association of dietary, circulating, and supplement fatty acids with coronary risk: a systematic review and meta-analysis. Ann Intern Med 160, 398-406.

19. de Souza RJ, Mente A, Maroleanu A et al. (2015) Intake of saturated and trans unsaturated fatty acids and risk of all cause mortality, cardiovascular disease, and type 2 diabetes: systematic review and meta-analysis of observational studies. BMJ 351, h3978.

20. Siri-Tarino PW, Sun Q, Hu FB et al. (2010) Meta-analysis of prospective cohort studies evaluating the association of saturated fat with cardiovascular disease Am J Clin Nutr 91, 535-546.

21. Jakobsen MU, O'Reilly EJ, Heitmann BL et al. (2009) Major types of dietary fat and risk of coronary heart disease: a pooled analysis of 11 cohort studies. Am J Clin Nutr 89, $1425-1432$

22. Jakobsen MU, Dethlefsen C, Joensen AM et al. (2010) Intake of carbohydrates compared with intake of saturated fatty acids and risk of myocardial infarction: importance of the glycemic index. Am J Clin Nutr 91, 1764-1768.

23. Dehghan M, Mente A, Zhang X et al. (2017) Associations of fats and carbohydrate intake with cardiovascular disease and mortality in 18 countries from five continents (PURE): a prospective cohort study. Lancet 390, 2050-2062.

24. Andersen LF, Solvoll K, Johansson LRK et al. (1999) Evaluation of a food frequency questionnaire with weighed records, fatty acids, and $\boldsymbol{\alpha}$-tocopherol in adipose tissue and serum. Am J Epidemiol 150, 75-87.

25. Rimestad AH (2001) Den store matvaretabellen (The big food table). In Statens råd for Ernoering og Fysisk Aktivitet, Statens Noeringsmiddeltilsyn, p. 156 [Institutt for ernæringsforskning, University of Oslo, editor]. Oslo: Gyldendal undervisning.

26. Johansson L, Borgejordet \& \& Perdersen JI (2006) Transfettsyrer i norsk kosthold (Trans fatty acids in the Norwegian diet). Tidsskr Nor Lageforen 126, 760-763.
27. Sulo G, Igland J, Vollset ST et al. (2013) Cardiovascular disease and diabetes mellitus in Norway during 1994-2009 CVDNOR - a nationwide research project. No Epidemiol 23, 101-107.

28. Sulo G, Igland J, Nygård O et al. (2014) Favourable trends in incidence of AMI in Norway during 2001-2009 do not include younger adults: a CVDNOR project. EJPC 21, 1358-1364.

29. Therneau T \& Grambsch PM (2000) Modeling Survival Data: Extending the Cox Model, 1st ed. New York, NY: Springer.

30. Faerch K, Lau C, Tetens I et al. (2005) A statistical approach based on substitution of macronutrients provides additional information to models analyzing single dietary factors in relation to type 2 diabetes in Danish adults: the Inter99 study. J Nutr 135, 1177-1182.

31. Sonestedt E, Överby NC, Birgisdottir BE et al. (2014) Chapter 11, Carbohydrates. In Nordic Nutrition Recommendations 2012, 5th ed., pp. 249-279 [Nordic Council of Ministers (NCM), editor]. Copenhagen: Norden.

32. Lande B, Munch AT \& Johansson L (2017) Utvikling i Norsk Kosthold 2017 (Development in the Norwegian Diet 2017). Oslo: Helsedirektoratet.

33. Johansson L, Solvoll K \& Teigum HM (1999) Norkost 1997 Landsomfattende kostholdsundersøkelse blant menn og kvinner $i$ alderen 16-79år (Norkost 1997 Nationwide Dietary Survey among Men and Women Aged 16-9 s). Oslo: Statens råd for ernæring og fysisk aktivitet.

34. Esrey KL, Joseph L \& Grover SA (1996) Relationship between dietary intake and coronary heart disease mortality: lipid research clinics prevalence follow-up study. J Clin Epidemiol 49, 211-216.

35. Li Y, Hruby A, Bernstein AM et al. (2015) Saturated fat as compared with unsaturated fats and sources of carbohydrates in relation to risk of coronary heart disease: a prospective cohort study. J Am Coll Cardiol 66, $1538-1548$.

36. Fung TT, Malik V, Rexrode KM et al. (2009) Sweetened beverage consumption and risk of coronary heart disease in women. Am J Clin Nutr 89, 1037-1042.

37. Narain A, Kwok CS \& Mamas MA (2016) Soft drinks and sweetened beverages and the risk of cardiovascular disease and mortality: a systematic review and meta-analysis. Int J Clin Pract 70, 791-805.

38. Te Morenga LA, Howatson AJ, Jones RM et al. (2014) Dietary sugars and cardiometabolic risk: systematic review and meta-analyses of randomized controlled trials of the effects on blood pressure and lipids. Am J Clin Nutr 100, 65-79.

39. Blomhoff R, Andersen LF, Iversen PO et al. (2010) Chapter 8, Melk og meieriprodukter (Milk and dairy products). In Kostråd for å Fremme Folkehelsen og Forebygge Kroniske Sykdommer, pp. 100-115 [Nasjonalt råd for ernæring, editor]. Oslo: St. Olavs plass.

40. Gibson RA, Makrides M, Smithers LG et al. (2009) The effect of dairy foods on CHD: a systematic review of prospective cohort studies. Br J Nutr 102, 1267-1275.

41. Alexander DD, Bylsma LC, Vargas AJ et al. (2016) Dairy consumption and CVD: a systematic review and meta-analysis. BrJ Nutr 115, 737-750.

42. Qin L-Q, Xu J-Y, Han S-F et al. (2015) Dairy consumption and risk of cardiovascular disease: an updated meta-analysis of prospective cohort studies. Asia Pac J Clin Nutr 24, 90-100.

43. Agerholm-Larsen L, Bell ML, Grunwald GK et al. (2000) The effect of a probiotic milk product on plasma cholesterol: a meta-analysis of short term intervention studies. Eur J Clin Nutr 54, 856-860.

44. Mozaffarian D \& Wu JHY (2018) Flavonoids, dairy foods, and cardiovascular and metabolic health: a review of emerging biologic pathways. Circ Res 122, 369-384. 
45. Geleijnse JM, Vermeer C, Grobbee DE et al. (2004) Dietary intake of menaquinone is associated with a reduced risk of coronary heart disease: the Rotterdam Study. J Nutr 134, 3100-3105.

46. Rosqvist $\mathrm{F}$, Smedman A, Lindmark-Månsson $\mathrm{H}$ et al. (2015) Potential role of milk fat globule membrane in modulating plasma lipoproteins, gene expression, and cholesterol metabolism in humans: a randomized study. Am J Clin Nutr 102, 20-30.

47. Chen M, Li Y, Sun Q et al. (2016) Dairy fat and risk of cardiovascular disease in 3 cohorts of US adults. Am J Clin Nutr 104, 1209-1217.

48. Schwab U, Uusitupa M, Halldorsson TI et al. (2014) Chapter 10, Fat and fatty acids. In Nordic Nutrition Recommendations 2012 Integrating Nutrition and Physical Activity, 5th ed., pp. 217-247 [Nordic Council of Ministers (NCM), editor]. Copenhagen: Norden.

49. Nigam PK (2011) Serum lipid profile: fasting or non-fasting? Ind J Clin Biochem 26, 96-97.
50. Willett W \& Lenart E (2013) Chapter 6: reproducibility and validity of food frequency questionnaires. In Nutritional Epidemiology, 3rd ed., pp. 96-134 [W Willett, editor]. New York, NY: Oxford University Press.

51. Song M \& Giovannucci E (2018) Substitution analysis in nutritional epidemiology: proceed with caution Eur J Epidemiol 33, 137-140.

52. Seidelmann SB, Claggett B, Cheng S et al. (2018) Dietary carbohydrate intake and mortality: a prospective cohort study and meta-analysis. Lancet Public Health 3, e419-e428.

53. Mazidi M, Katsiki N, Mikhailidis DP et al. (2019) Lower carbohydrate diets and all-cause and cause-specific mortality: a population-based cohort study and pooling of prospective studies. EHJ 40, 2870-2879.

54. Sulo G, Igland J, Vollset SE et al. (2018) Trends in incident acute myocardial infarction in Norway: an updated analysis to 2014 using national data from the CVDNOR project. EurJ Prev Cardiol 25, 1031-1039. 